\title{
Estrutura social no Brasil: mudanças recentes
}

\section{Social structure in Brazil: recent changes}

Marcio Pochmann*

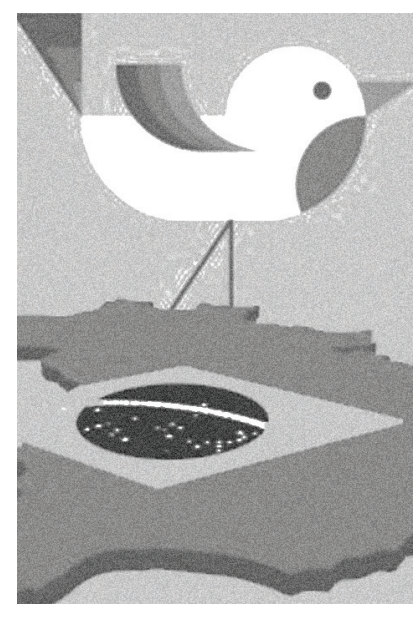

Resumo: O estudo busca identificar o novo padrão de mobilidade social que se encontra em curso no Brasil. Para isso, recupera brevemente seus principais elementos determinantes, assim como procura destacar as características centrais observadas nos segmentos populacionais.

Palavras-chave: Mobilidade. Desigualdade. Renda. Pobreza.

\begin{abstract}
This article tries to identify the new pattern of social mobility in progress in Brazil. To do that, it recovers its main determining elements briefly, as well as it tries to emphasize the central characteristics observed in the population segments.
\end{abstract}

Keywords: Mobility. Inequality. Income. Poverty.

* Professor licenciado do Instituto de Economia e do Centro de Estudos Sindicais e de Economia do Trabalho da Universidade Estadual de Campinas (Unicamp), Campinas/SP, Brasil; presidente do Instituto de Pesquisa Econômica Aplicada (Ipea).E-mail: pochmann@eco.unicamp.br. 
recuperação da dinâmica de expansão da economia e, por consequência, do emprego, combinada com a reorientação das políticas públicas aos segmentos de menor rendimento trouxeram mudanças recentes à estrutura social brasileira. A ascensão social aponta, por exemplo, para novas alterações na identidade social mais inclusiva.

Nesse sentido, o presente artigo ressalta as principais inflexões observadas na trajetória da mudança na estrutura e trajetória social do país. Inicialmente descreve a existência de diferentes padrões de mudança social observados no Brasil durante os últimos cinquenta anos, para, em na sequência, apresentar as principais características recentes da mudança social. Além de destacar a utilização de fontes de informações originárias do IBGE, cabe agradecer o apoio de vários técnicos do Ipea para a realização do presente ensaio.

\section{Padrões de mudança social no Brasil}

O Brasil não se encontra entre os países de baixa trajetória de mudança social. Em termos internacionais, registra-se que o indicador de mobilidades social do conjunto da população apresenta-se muito diferenciado entre as nações. ${ }^{1}$ Ao se utilizar parâmetros relativamente homogêneos de medida da mobilidade social nacional, pode-se constatar que o Brasil localiza-se entre os países com as mais altas taxas de mudança social.

Numa mostra de quinze países verifica-se que o Brasil registra a mais alta taxa de mobilidade social $(63,2 \%)$, acima de países como Suécia $(51,5 \%)$ e Canadá (50,1\%). No ano de 1996, por exemplo, no Brasil, a imobilidade social respondia por uma taxa inferior a $40 \%$.

A taxa de mudança social brasileira chega a ser 50\% superior ao grau de mobilidade das nações pertencentes ao grupo intermediário, como Espanha (40,7\%), França $(43,7 \%)$ e Estados Unidos (48,2\%). Se considerado o grupo de países de baixa mobilidade, como Bélgica (37\%), Inglaterra $(37,6 \%)$ e Dinamarca $(37,9 \%)$, a taxa de mobilidade social brasileira pode ser quase duas vezes maior.

1. Sobre isso, ver mais em: Carlsson, 1958; Sorokin, 1927; Goldthorpe, 1981; Boudon, 1973; Glass, 1954; Heath, 1981; Blau e Duncan, 1967; Merlli e Prévot, 1997. 
Gráfico 1

Indicador de mobilidade social em países selecionados (em \%)

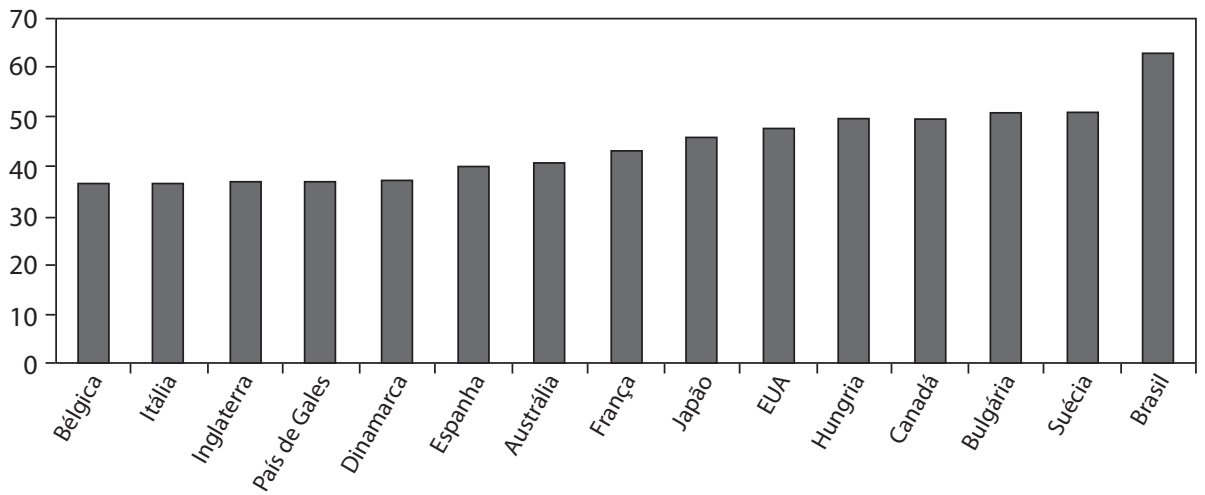

Fonte: IBGE (PNAD, 1996); Heath, 1981.

Para além do reconhecimento de que a mobilidade social é elevada no Brasil em relação a outros países, deve-se procurar identificar se há um ou mais padrões de mudança social. Como padrão de mobilidade social entende-se a alteração de posições de distintos segmentos populacionais no interior da estrutura social.

Gráfico 2

Brasil — Índice de evolução da renda nacional por habitante e da desigualdade pessoal da renda (Gini) entre 1960 e 2009 (1960 = 100)

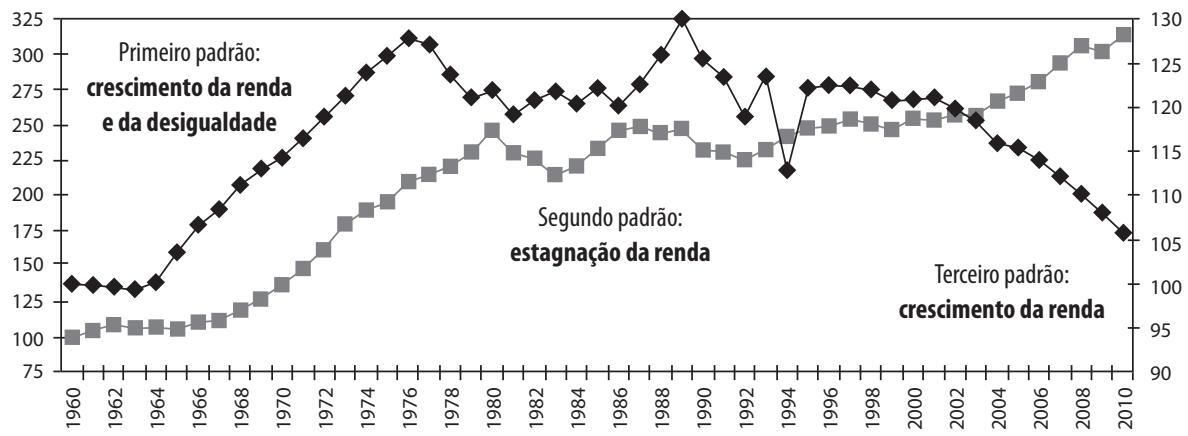

- renda por brasileiro desigualdade de renda

Fonte: IBGE (elaboração própria). 
Partindo do pressuposto básico de que o grau de mudança social tende a refletir, em geral, transformações mais amplas na economia (renda, ocupação etc.) e nas políticas públicas (educação, garantia de renda etc.), tomou-se com referência síntese disso os indicadores de variação da renda nacional per capita e do índice de desigualdade pessoal da renda (Gini). Com base nisso, nota-se que o Brasil apresentou três diferentes padrões de mudança social nos últimos cinquenta anos.

O primeiro padrão de mudança social se caracterizou por forte expansão da renda per capita acompanhada de significativo crescimento da desigualdade na repartição da renda pessoal. Durante os anos 1960 e 1980, o Brasil seguiu orientado pelo avanço do projeto de industrialização nacional, com importante impacto decorrente do movimento geral de urbanização. ${ }^{2}$

A transição populacional do campo para a cidade ocorreu em simultânea ampliação da estrutura ocupacional urbana, especialmente puxada pelo setor industrial e pela construção civil. Da mesma forma, o setor terciário (comércio e serviços urbanos) cresceu consideravelmente, permitindo que as novas ofertas de emprego fossem superiores, em geral, aos postos de trabalho do meio rural, não obstante o predomínio da baixa remuneração dos empregados nas cidades. No período de 1960 a 1980, por exemplo, o valor real do salário mínimo teve queda média anual de 1,6\%, embora a ocupação total tenha aumentado 3,1\% com média anual.

Mesmo com a redução na taxa de pobreza $(-1,3 \%$ ao ano) e a elevação nos anos de escolaridade dos brasileiros, o grau de desigualdade na renda pessoal aumentou $1 \%$ ao ano durante o mesmo período. Em função disso, o padrão de mobilidade de mudança social verificado até o final da década de 1970 caracterizou-se pelo forte contraste entre a rápida elevação da renda nacional por habitante e o forte aumento no grau de desigualdade na repartição dos frutos do crescimento econômico.

O segundo padrão de mudança social ocorreu entre os anos 1981 e 2003. Durante esse período, predominou a estagnação na variação da renda per capita acompanhado do estancamento do grau de desigualdade na repartição da renda pessoal. Esse quadro geral resultou em alta oscilação no comportamento

2. Sobre isso, ver: Fernandes, 1979; Lopes, 1971; Pastore, 1979; Silva, 1979; Haller e Saraiva, 1988; Pastore e Zylberstain, 1990; Barros et al., 1992. 


\section{Gráfico 3}

Brasil: Índices de variação média anual dos componentes da mobilidade social (em \%)

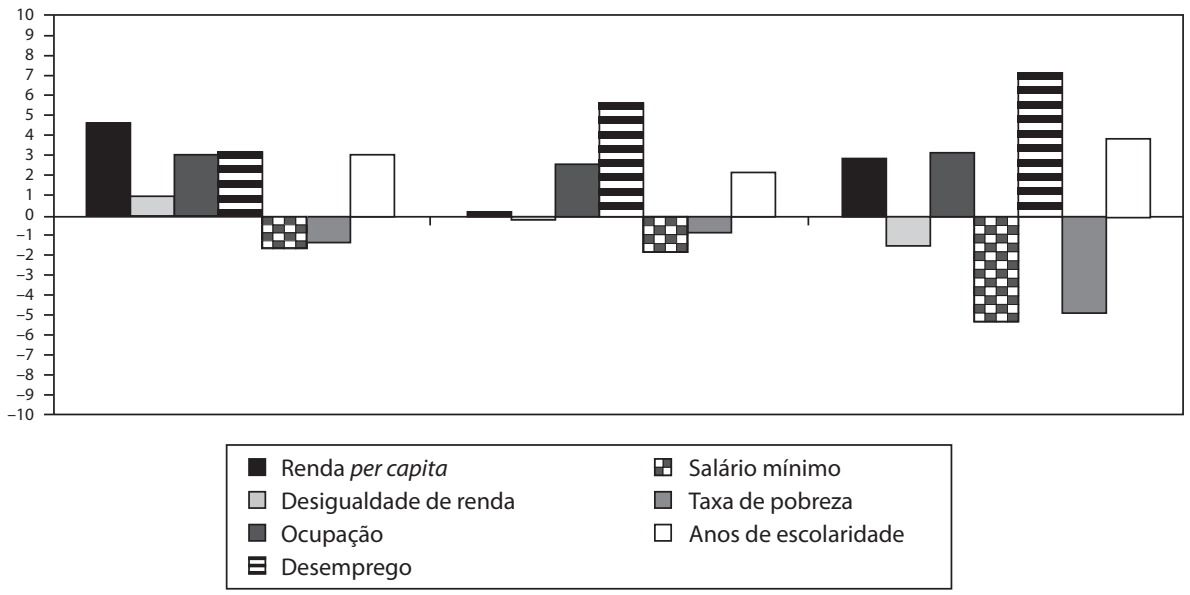

Fonte: IBGE, Dieese, Ipea (elaboração própria).

da renda per capita e no grau de desigualdade, tendo em vista o predomínio do regime de superinflação até 1994 e de crises econômicas, que rebaixaram a renda gerada, como em 1981-83, 1990-92, 1998-99 e 2002-03.

Para uma variação média anual de $0,2 \%$ na renda nacional per capita, a desigualdade de renda caiu $0,1 \%$. Ao mesmo tempo, constata-se que o desemprego da força de trabalho foi o que mais cresceu $(5,6 \%)$, com elevação do nível ocupacional $(2,6 \%)$ demarcada pela precariedade e queda do valor real do salário mínimo $(1,8 \%)$. A taxa de pobreza caiu $(0,8 \%)$, porém com ritmo inferior ao verificado entre 1960 e 1980 (1,3\%), assim como no caso dos anos de escolaridade seguiu crescendo abaixo do primeiro padrão de mudança social. Nessa fase, a mobilidade social cresceu menos, com sinais crescentes de imobilidade para determinados segmentos dos brasileiros. ${ }^{3}$

Desde o final da primeira metade da década de 2000 observa-se o surgimento de um novo padrão de mudança social no Brasil. Esse terceiro padrão possui como características principais a combinação da expansão da renda

3. Mais detalhes em: Scalon, 1999; Ribeiro, 2003; Santos, 2002; Quadros, 2008; Amorim e Pochmann, 2003; Campos et al., 2003; Guerra et al., 2006. 
nacional per capita com a queda na desigualdade pessoal da renda. Para os anos de 2004 e 2010, a renda per capita cresceu 2,9\% como média anual, enquanto a desigualdade da renda pessoal caiu 1,5\% em média ao ano. Com isso, observa-se também tanto a redução média anual da taxa de desemprego $(5,2 \%)$ e da pobreza $(4,8 \%)$, como o forte aumento médio anual no valor real do salário mínimo $(7,1 \%)$, na ocupação $(3,2 \%)$ e nos anos de escolaridade $(3,8 \%)$ dos brasileiros.

Em grande medida, o melhor desempenho nos indicadores de mobilidade social encontra-se fortemente associado ao conjunto de transformações na economia e nas políticas públicas. De um lado, a recuperação do ritmo de crescimento econômico desde 2004 foi estimulado pelos investimentos e pela ampliação do mercado interno de consumo, sustentado pela elevação da renda das famílias. O retorno do fortalecimento do setor industrial permitiu não apenas estimular o nível de emprego, mas também melhorar a qualidade das ocupações geradas, predominantemente formais. Entre 2004 e 2009, por exemplo, houve a geração líquida de 8,1 milhões de postos de trabalho formais, enquanto entre 1998 e 2003 foram criados apenas 1,9 milhão de novos empregos assalariados com carteira assinada em todo o Brasil.

De outro lado, houve ampliação da renda das famílias, sobretudo daquelas situadas na base da pirâmide social, em decorrência do papel ativo das políticas

\section{Gráfico 4}

Brasil: Variação do rendimento médio mensal real familiar per capita por decil de 1995 a 2002 e de 2003 a 2008 (em\%)

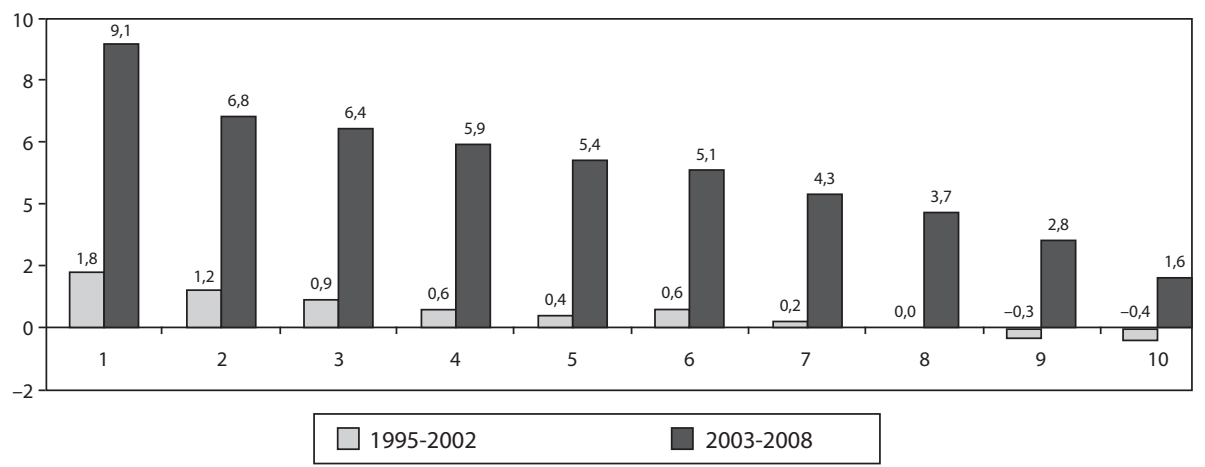

Fonte: IBGE PNAD (elaboração própria). 
públicas. Enquanto o rendimento médio familiar per capita no topo da distribuição da renda (10\% mais ricos) no Brasil cresceu 1,6\%, em média, entre 2003 e 2008, o rendimento médio familiar per capita na base da distribuição da renda no Brasil (10\% mais pobres) cresceu 9,1\% ao ano, em media. Inicialmente, devido à política de aumento do valor do salário mínimo, que permitiu injetar R\$ 1 trilhão nos rendimentos de trabalhadores de salário de base somente no período de 2003 a 2010 . Na sequência, a política de transferência direta de renda aos diversos segmentos vulneráveis (idosos, portadores de necessidades especiais, desempregados e pobres) por meio da Previdência e Assistência Social. Entre os anos 2002 e 2008, por exemplo, a transferência de renda aos segmentos mais vulneráveis da população foi nominalmente multiplicada por 2,3 vezes, passando de R \$ 134,7 bilhões para R \$ 305,3 bilhões.

Por fim, destaca-se ainda a recente adoção da política de inclusão bancária, capaz de elevar a difusão do crédito tanto para o consumo como para a produção, especialmente dos segmentos de baixa renda. A presença das operações de crédito no total do Produto Interno Bruto passou de 24,2\% em 2002 para 45\% em 2009. Com isso, o volume de recursos pertencente aos financiamentos destinadas às pessoas físicas foi multiplicado por mais de quatro vezes entre 2003 e 2009, enquanto o repasse de recursos à agricultura familiar passou de $\mathrm{R} \$ 2,4$ bilhões, em 2003, para R \$10,8 bilhões em 2009. Também no âmbito das operações de crédito, cabe ressaltar o avanço do financiamento para a habitação, que passou de R\$25,7 bilhões em 2004 para R\$ 80 bilhões em 2009.

Em síntese, nota-se que o terceiro padrão de mudança social atualmente em curso encontra-se fortemente relacionado ao apoio ocupacional, educacional e de renda à base da estrutura ocupacional brasileira. Conforme já demonstrado pela literatura especializada, a convergência de política pública no segmento social definido por working poor apresenta grande potencial de impor novo padrão de mudança social. ${ }^{4}$ Isso parece ser mais real quando se constata que durante o período o segundo padrão de mudança social, entre 1981-2003, os trabalhadores de salário de base terminaram sendo os mais atingidos negativamente pelo quadro geral de estagnação da renda per capita e contração do mercado de trabalho e do valor do salário mínimo. ${ }^{5}$

\footnotetext{
4. Ver Kazis e Miller, 2001; Galbraith e Berner, 2001; Pochmann, 2010.

5. Sobre isso, ver Guerra et al., 2007; Pochmann, 2009; Quadros, 2009.
} 


\section{Principais sinais de mudança na estrutura social}

Para registrar os principais sinais de mudança social recente no Brasil utilizou-se o procedimento metodológico adotado anteriormente, ou seja, a repartição do conjunto da população brasileira em três partes, segundo diferentes níveis de rendimento (Amorim e Pochmann, 2009). Na primeira parte encontra-se o segmento cujo rendimento individual alcança até $\mathrm{R} \$ 188$ mensais no ano de 2008, enquanto a segunda parte compreende o segmento de rendimento intermediário, que perfaz o intervalo de $\mathrm{R} \$ 188$ a $\mathrm{R} \$ 465$ mensais. $\mathrm{Na}$ terceira parte localiza-se o segmento com rendimentos individuais acima de $\mathrm{R} \$ 465$ mensais.

Quando se considera o comportamento dos três diferentes grupamentos de rendimento da população entre 1995 e 2008 (baixo, intermediário e superior), constata-se uma modificação importante desde 2005, especialmente no estrato social de menor renda. No período de 1997 a 2004, por exemplo, o segmento de baixa renda abrangia aproximadamente $34 \%$ da população nacional, mas desde 2005 passou a reduzir rapidamente a sua participação relativa. Em 2008 o segmento de menor renda representou apenas $26 \%$ dos brasileiros, a menor participação relativa desde 1995.

A participação relativa da população na base da pirâmide social encolheu $22,8 \%$ entre 2005 e 2008, resultado direto da mobilidade ascensional de 11,7 milhões de pessoas para estratos de maior renda. Em função disso, percebe-se que o segundo (médio) e o terceiro (alto) estratos de renda ganharam maior representatividade populacional. A partir de 1997, o estrato intermediário de renda cresceu relativamente a sua participação até o ano de 2005, quando apresentou um salto expressivo. Em 2008, por exemplo, o segundo estrato de renda representou $37,4 \%$ da população, enquanto em 1995 respondia por somente 21,8\%. Entre o anos de 2004 (34,9\%) e de 2008 (37,4\%), o estrato intermediário registrou uma elevação relativa de $7,2 \%$ no total da população, que equivaleu a incorporação de 7 milhões de brasileiros.

Já o estrato superior de renda que apresentava tendência de perda relativa de participação populacional entre 1998 e 2004, saindo de 35,3\% para 31,5\% da população, passou, a partir de 2005, a recuperar posição relativa. Para 2008, por exemplo, o estrato superior respondeu por $36,6 \%$ do total da população brasileira, a mais alta participação registrada desde 1995. No período de 2004 


\section{Gráfico 5}

Brasil — Evolução da estrutura social segundo três níveis de renda de 1995 a 2008 (total = 100\%)



Fonte: IBGE — PNAD (elaboração Ipea). Base = até R\$ 188 mensais per capita; Intermediária $=$ de $\mathrm{R} \$ 188$ a R\$ 465; e Superior $=$ acima de $R \$ 465$.

$(31,5 \%)$ a $2008(36,6 \%)$, o crescimento da participação relativa foi de $16,2 \%$, ou o equivalente a 11,5 milhões de brasileiros absorvidos no estrato superior de renda.

Em síntese, percebe-se que somente entre 2005 e 2008, 11,7 milhões de brasileiros abandonaram a condição de menor renda, enquanto 7 milhões de indivíduos ingressaram no segundo estrato de renda e 11,5 milhões de pessoas transitaram para o estrato superior. Com o recente retorno da mobilidade social ascendente no Brasil, convém considerar o quanto isso vem impactando a estrutura social. Para tanto, buscou-se comparar a estrutura social de $2008 \mathrm{com}$ a de 1998, o que permitiu observar as principais transformações dos últimos dez anos da sociedade brasileira.

Considerando-se o local de moradia dos brasileiros, nota-se que o meio rural ampliou a presença no segmento de maior renda, pois passou de $6,2 \% \mathrm{em}$ 1998 para $6,4 \%$ em 2008. Nos estratos de menor renda, a população do campo 
perdeu posição relativa para o meio urbano. As regiões metropolitanas aumentaram o peso relativo no estrato de menor renda, passando de 17,3\%, em 1998, para 20,5\%, em 2008, bem como perderam peso na representação da população com maior renda (42,8\%, em 1998, para 38,6\%, em 2008). Enquanto os municípios médios não registram grandes alterações relativas no período considerado, os pequenos municípios apresentaram modificações importantes. De um lado, reduziram o peso relativo no total da população na base da pirâmide social (de 66,8\% em 1998, para 63,8\% em 2008) e, por outro, elevaram a participação relativa da população no estrato superior de renda (de 30,5\% em 1998, para $35,6 \%$ em 2008).

No que se refere à distribuição da população por grandes regiões geográficas, percebe-se modificações na composição do estrato superior de renda, com decréscimo significativo da região Sudeste (de 58,1\% em 1998, para 53,2\% em 2008). Em compensação, a maior presença da região Sul (18,6\% em 1998, para $20 \%$ em 2008), do Norte (de 3,6\%, em 1999, para 5,2\%, em 2008), do Nordeste (de 12,6\% em 1998, para 13,6\% em 2008) e Centro-Oeste (de 7,1\% em 1998, para $8,1 \%$ em 2008).

Apesar da mudança relativa da população no estrato de alta renda, a Região Nordeste continuou representando 50,9\% do total dos brasileiros na base da pirâmide social entre 1998 e 2008. No mesmo período, a Região Norte foi a única que apresentou aumento relativo da população no estrato de menor renda.

Na distribuição da população segundo o gênero, observa-se que os homens reduziram o peso no menor estrato de renda (de 49,2\%, em 1998, para 48,7\%, em 2008) e aumentaram no estrato superior (de 48,9\%, em 1998, para 49\%, em 2008). As mulheres somente conseguiram melhorar a posição relativa no segmento de renda intermediário (de 50,9\% em 1998, para 51,5\% em 2008).

Por faixa etária, constata-se queda na participação relativa do segmento de até nove anos de idade na base da pirâmide social (28,7\% em 1998, para $26,6 \%$ em 2008). Por outro lado, houve elevação no estrato de maior renda para os segmentos com 45 anos e mais de idade (de 27,7\% em 1998, para 36,6\% em 2008).

No quesito escolaridade, nota-se que o segmento populacional com onze anos e mais de escolaridade cresceu sua participação relativa tanto no estrato de maior renda (de 40\% em 1998, para 55\% em 2008) como também elevou a presença na base da pirâmide social (de 3,7\% em 1998, para 12,4\% em 2008). 
O segmento sem escolaridade decresceu sua participação relativa em todos os estratos de renda.

No que se refere à distribuição da população entre 1998 e 2008 segundo a condição de atividade, verifica-se como a ocupação tornou-se ainda mais decisiva para o posicionamento na estrutura social. Os ocupados, que concentravam $65 \%$ da população do estrato superior de renda, em 1998, representaram $70,2 \%$ em 2008. Da mesma forma, os ocupados diminuíram o peso relativo na base da pirâmide social (de 56,1\% em 1998, para 54,3\% em 2008).

Os inativos e desempregados, em compensação, elevaram o peso na base da pirâmide social. Por outro lado, os não ocupados diminuíram a participação relativa no estrato superior de renda entre 1998 e 2008.

Os empregados perderam participação relativa entre as pessoas com menor renda (de 49,7\% em 1998, para 45,4\% em 2008), bem como no estrato de menor renda (de 58,6\% em 1998, para 55,7\% em 2008). Em compensação, os trabalhadores sem remuneração aumentaram o peso relativo na base da pirâmide social, enquanto os empregadores e conta própria elevaram a participação no estrato de renda superior.

No critério cor/ração identifica-se uma mudança importante na estrutura social brasileira durante o período analisado. Enquanto a população negra aumentou o peso relativo nos três estratos renda, sobretudo no superior (de 25,6\% em 1998, para 33,7\% em 2008), os brancos reduziram relativamente em todos os estratos de renda.

Na distribuição da população segundo a condição de ocupação do domicílio, verifica-se que para aqueles com posse do imóvel ocorreu redução na participação relativa nos estratos de menor renda (baixo e intermediário), enquanto houve elevação no estrato de maior renda. Para a população com imóvel alugado, registrou-se, entre 1998 e 2008, o aumento na participação relativa da classe baixa, ao mesmo tempo em que caiu o peso relativo da população com imóvel cedido na base da pirâmide social.

Com relação aos bens de consumo duráveis, observa-se que a posse de fogão, geladeira e rádio, as diferenças entre os diferentes níveis de renda não são acentuadas. O mesmo não pode ser dito com base na posse da máquina de lavar e telefone. Este, por sinal, registrou avanço significativo entre 1998 e 2008. 


\section{Considerações finais}

Em conformidade com as páginas anteriores, foi possível identificar a presença da mobilidade social no Brasil. Entre 1960 e 2010 pode ser destacada a existência de três padrões distintos de mudança social no país. O primeiro, que se deu entre 1960 e 1980, revela a elevada expansão da renda nacional per capita com forte expansão da desigualdade de renda da pessoa, enquanto o segundo padrão, que ocorreu entre os anos de 1981 e 2003, foi caracterizado pela estagnação da renda nacional per capita e contenção da desigualdade, ainda que exposta a forte oscilação. Por fim, o terceiro padrão de mudança social que se encontra em curso desde 2004 demarca a combinação entre o crescimento da renda nacional per capita a redução importante da desigualdade pessoal da renda.

As principais características desse movimento recente de mudança social foram apresentadas, permitindo observar que ele não ocorre homogeneamente entre faixa etária, sexo, ocupação, condição de moradia, cor e região. De todo o modo, a mobilidade social ascendente revela a transformação maior que se verifica no âmbito tanto da economia como das políticas públicas. Em síntese, a convergência econômica e política de eventos direcionados justamente à base da pirâmide social brasileira.

Artigo recebido em ago./2010 - Aprovado em ago./2010

\section{Referências bibliográficas}

AMORIM. R.; POCHMANN, M. Atlas da exclusão social no Brasil. Cortez: São Paulo, 2003.

. Pobreza e mudanças sociais recentes no Brasil. In: CASTRO, J.; RIBEIRO, J. (Orgs.). Situação social brasileira, 2007. Brasília: Ipea, 2009.

BARROS, R. et al. Mobilidade de renda no Brasil. Rio de Janeiro: ISLMRPI, 1992.

BLAU, P.; DUNCAN, O. The american occupational structure. New York: JW, 1967. BOUDON, R. L'inégalité des chances. Paris: A. Colin, 1967.

CAMPOS, A. et al. Atlas da exclusão social no Brasil: dinâmica e manifestação territorial. São Paulo: Cortez, 2003. 
CARLSSON, G. Social mobility and class structure. Lund: CWK, 1958.

FERNANDES. F. Mudanças sociais no Brasil. São Paulo: Difel, 1979.

GALBRAITH, J.; BERNER, M. Inequality \& industrial change. Cambridge: CUP, 2001

GLASS, D. Social mobility in Britain. London: R\&KP, 1954.

GOLDTHORPE, J. Social mobility and class structure in modern Britain. Oxford: Claredon Press, 1981.

GUERRA, A. et al. Classe média: desenvolvimento e crise. São Paulo: Cortez, 2006. . Trabalhadores urbanos: ocupação e queda na renda. São Paulo: Cortez, 2007.

HALLER, A.; SARAIVA, H. The income effects of education in development: Brazil 1973 and 1980. SI: sn., 1988.

HEATH, A. Social mobility. Glasgow: FP, 1981.

KAZIS, R.; MILLER, M. Low-Wage Workers. Washington: UIP, 2001.

LOPES, J. Desenvolvimento e mudança social. São Paulo: Nacional, 1971.

MERLLIÉ, D.; PRÉVOT, J. La mobilité sociale. Paris: La Découverte, 1997.

PASTORE, J. Desigualdade e mobilidade social no Brasil. São Paulo: Ed. USP, 1979. ; ZYLBERSTAIN, H. Social mobility in Brazil 1973-1982: the role of education in status determination. São Paulo: Ed. USP, 1990.

POCHMANN, M. What Brazil learned from labour flexibilization in the 1990s. International Labour Review, v. 148, n. 3, set. 2009.

. Desenvolvimento e perspectivas novas para o Brasil. São Paulo: Cortez, 2010.

QUADROS, W. A evolução recente da estrutura social brasileira. TD, Campinas, Unicamp, n. 148, 2008.

. Perfil social do desemprego recente. TD, Campinas, Unicamp, n. 156, 2009.

RIBEIRO, C. Estrutura de classe e mobilidade social no Brasil. Bauru: Edusc, 2003.

SANTOS, J. Estrutura de posições de classe no Brasil. Belo Horizonte: Ed. UFMG, 2002.

SCALON, M. (1999) Mobilidade social no Brasil. Revan: Rio de Janeiro.

SILVA, N. As duas faces da mobilidade social. Dados, Rio de Janeiro, n. 21, 1979.

SOROKIN, P. Social Mobility. New York: Harper \& Brothers, 1927. 